\title{
Triple Synchronous Tumors Presenting as Right Nasolabial Basal Cell Carcinoma, Papillary Thyroid Carcinoma and Prolactinoma: A Rare Case Report
}

\author{
Mateo Te III, Donnah Bless Lumanlan-Mosqueda, Kenny Jun Demegillo \\ Department of Internal Medicine, Southern Philippines Medical Center, Davao City, Philippines
}

\begin{abstract}
Multiple primary tumors are rare, with a published meta-analysis that shows the frequency of second primary tumor at $3-5 \%$, and a third tumor at $0.5 \%$. A 57 -year-old female sought consultation due to a persistently bleeding right nasolabial mass. On further history and examination, she also presented with a right anterior neck mass, repeated abortions, secondary amenorrhea, and loss of libido years prior. Serum prolactin was significantly elevated and an incidental finding of a pituitary mass on head and neck CT scan was appreciated. Metastasis and syndromic familial disorder were ruled out. Bromocriptine was given and she underwent total thyroidectomy and wide excision of the right nasolabial mass which turned out to be papillary thyroid carcinoma (PTC) and basal cell carcinoma (BCC) respectively on histopathologic report. On follow up, repeat serum prolactin decreased to normal levels. After extensive literature review, this is the first documented case of triple synchronous tumors with a combination of BCC of the right nasolabial area, PTC and prolactinoma in local, national and international studies. With comprehensive work up and literature search, the diagnosis was established and ultimately the patient benefited from a multidisciplinary management.
\end{abstract}

Key words: multiple primary, synchronous tumors

\section{INTRODUCTION}

A reported meta-analysis of multiple primary tumors show the frequency of second primary tumor as 3-5\%, a third tumor as $0.5 \%$ and a fourth tumor as $0.3 \%{ }^{1,2}$ This is a rare case of triple synchronous tumors consisting of basal cell carcinoma of the right nasolabial area, papillary thyroid carcinoma and prolactinoma in a 57-year-old female who presented with infertility, amenorrhea, and loss of sexual desire in the absence of galactorrhea. The incidence of the individual tumor presented is relatively common however this case report highlights that the combination of three common tumors in a single patient is a rare occurrence.

Approaching different tumors involving multiple endocrine organs is challenging. Hence this case report features the diagnostic approach to classifying the nature of multiple tumors whether primary, metastatic or syndromic.

The need to utilize an objective and standardized classification and diagnosis of multiple primary tumors is important. Thus, the definition given by the International Association of Cancer Registries (IACR) was utilized. A 6-month rule interval to diagnosing synchronous from metachronous tumors arising from different sites regardless of the time of onset is observed. ${ }^{3}$ The patient had three primary tumors of different germline origins and locations. The manifestation of each tumor has different timeline of appearance however all three tumors were already manifested by the patient and were diagnosed within 6 months during the work up hence considered synchronous.

\section{CASE}

A 57-year-old, female, sought consultation due to a persistently bleeding right nasolabial mass.

Five years prior to admission (PTA), a small dark mole was noted by the patient on her right nasolabial area which progressively grew in size to $3 \times 4 \mathrm{~cm}$ over five years. The mass ruptured, ulcerated and bled out. Persistent bleeding prompted the consultation.

Past medical history revealed 15 years PTA, a $1 \times 1 \mathrm{~cm}$ smooth, non-tender mass was appreciated over the anterior right side of the neck that moved with deglutition. Increase in size, prompted consultation at a local hospital. Fine needle aspiration biopsy (FNAB) was done however she was lost to follow up.

Heredo-familial diseases in the family only revealed a maternal aunt with thyroid cancer of unknown histopathology (Appendix A). She is a street vegetable peddler. She is a non-smoker and non-alcoholic beverage drinker.
ISSN 0857-1074 (Print) I eISSN 2308-118x (Online)

Printed in the Philippines

Copyright (C) 2020 by Te III et al.

Received: July 26, 2020. Accepted: September 30, 2020.

Published online first: October 20, 2020.

https://doi.org/10.15605/jafes.035.02.08
Corresponding author: Mateo C. Te III, MD

Senior Resident, Department of Internal Medicine

Southern Philippines Medical Center

JP Laurel Avenue, Bajada, Davao City, 8000, Davao del Sur

Tel. No.: 082 227-2731

E-mail: iamthethird.matt@gmail.com

ORCiD: https://orcid.org/0000-0002-0411-8597 
Her perinatal history was unremarkable. Her developmental milestones were at par with her peers. She developed secondary sexual characteristics and growth spurt almost at the same rate as her female peers.

Her menarche was at the age of 12 years old, with unremarkable menstrual pattern. The patient's obstetric profile is G4P0.

\begin{tabular}{|c|c|c|}
\hline G1 & 1981 & Spontaneous abortion at 8 weeks \\
\hline G2 & 1982 & Spontaneous abortion at 8 weeks \\
\hline G3 & 1984 & Spontaneous abortion at 8 weeks \\
\hline G4 & 1996 & $\begin{array}{l}\text { Spontaneous abortion at } 16 \text { weeks and underwent } \\
\text { dilatation and curettage with minimal blood loss }\end{array}$ \\
\hline
\end{tabular}

After her miscarriages (Figure 1), she had amenorrhea at the age of 26 which was associated with loss of sexual desire. There were no headache, dizziness, visual abnormalities, and galactorrhea.

She was examined awake with normal vital signs, and with a body mass index of $29.3 \mathrm{~kg} / \mathrm{m}^{2}$ (obese 1 for Asians). As depicted on Figure 2, pertinent physical findings revealed a pedunculated mass with rolled up edges and central ulceration on the right nasolabial area. A nodular, non-tender mass was palpated over the right anterior neck that moved with deglutition. There were no cervical lymphadenopathies and neck vein distension. Breast and female genitalia examination were unremarkable (Tanner V).

\section{2}

- 4 consecutive spontaneous abortions

- Secondary amenorrhea at the age of 26

- Loss of libido

- (-) Galactorrhea and visual symptoms
- Progressive growth of thyroid mass

- FNAB done - unrecalled result

- Lost to follow up

\section{8}

- Ulcerating and persistently bleeding mass over the right nasolabial area

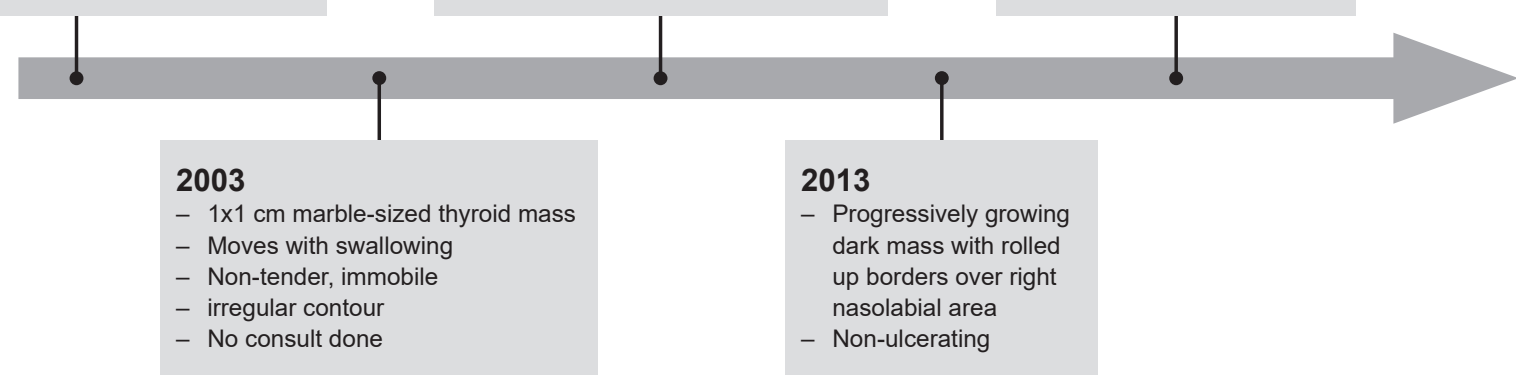

Figure 1. History timeline.
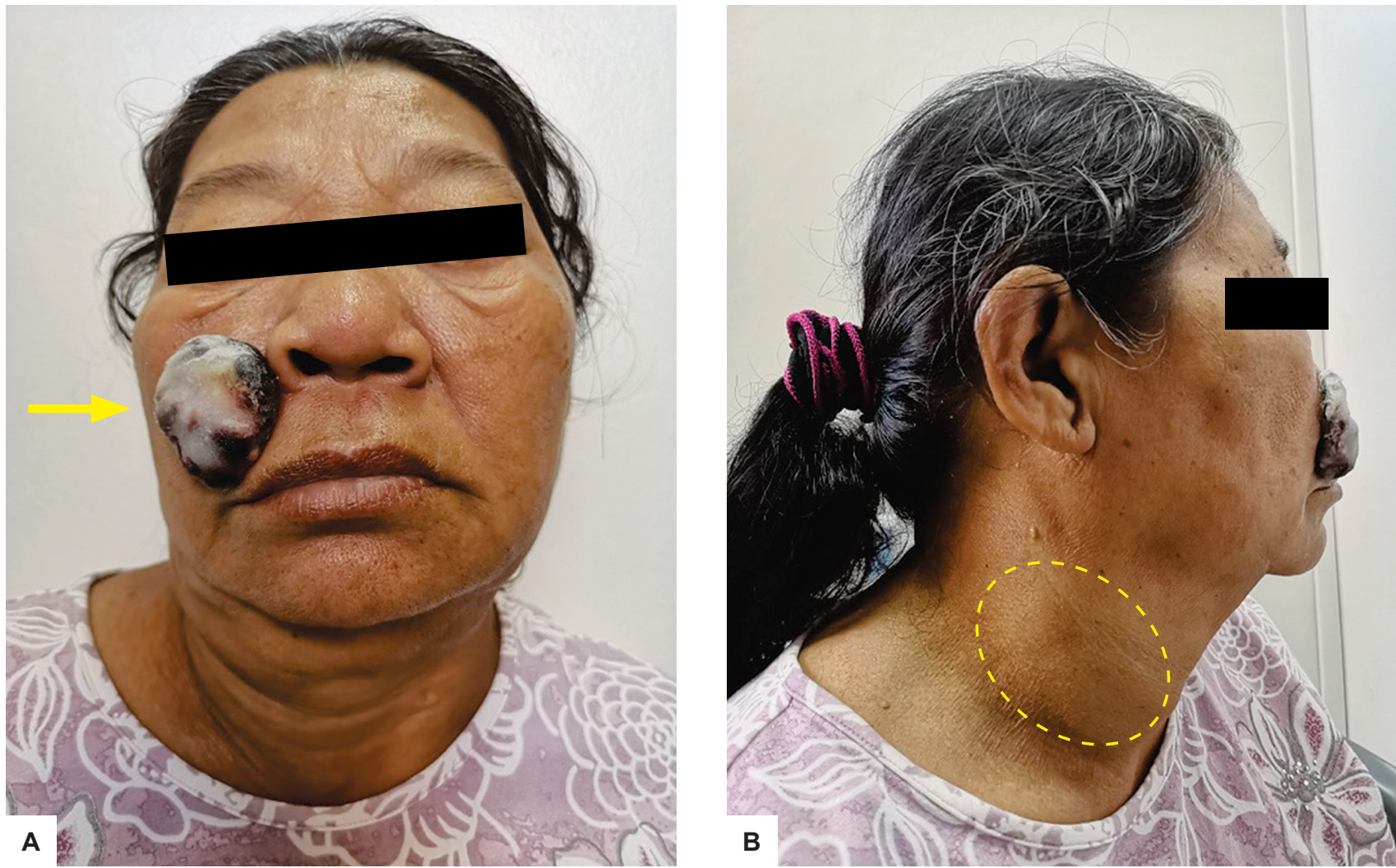

Figure 2. (A) $3 \times 4 \mathrm{~cm}$ pedunculated mass with rolled up borders and central ulceration (right nasolabial area); (B) $6 \times 5 \mathrm{~cm}$ nodular mass (right anterior neck). 
Visual acuity was 20/20 and peripheral vision was intact. The rest of the neurologic physical examination was unremarkable.

She was admitted with a working impression of right nasolabial mass to consider basal cell carcinoma; and anterior neck mass secondary to nodular nontoxic goiter; to consider malignancy.

Basic laboratory examination showed an elevated fasting blood sugar and glycosylated haemoglobin (HbA1c) at $7.4 \mathrm{mmol} / \mathrm{L}$ and $7 \%$; respectively. The ECG and chest X-ray were unremarkable. Wedge biopsy of the right nasolabial mass and an FNAB of the thyroid mass revealed basal cell carcinoma and papillary thyroid carcinoma, respectively.

Head and neck CT scan with contrast revealed an ulcerating mass over the right nasolabial area, a mass over the right thyroid lobe, and an incidental finding of a mass over the left parasellar area (Figure 3).

In view of an incidental finding of a sellar mass, a cranial Magnetic Resonance Imaging (MRI) was performed, revealing a poorly defined complex mass in the sella as shown in Figure 4.
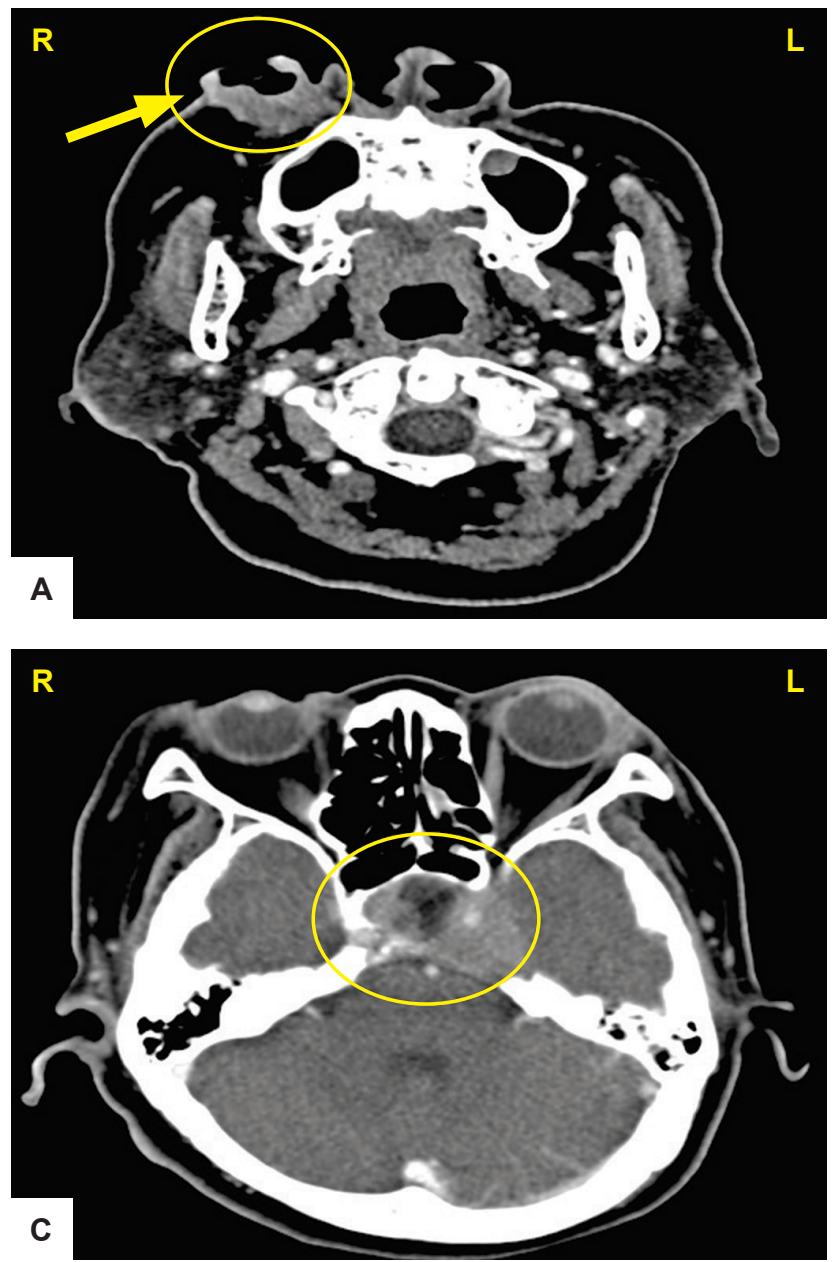

As summarized in Table 2, serum prolactin was markedly elevated. At this point hyperprolactinaemia from prolactinoma secondary to pituitary macroadenoma was considered. Hence patient was started on bromocriptine $2.5 \mathrm{mg} / \mathrm{tab}$; 1/2 tablet twice a day. Serum LH, $\mathrm{FSH}$, and cortisol were low. Intact parathyroid hormone was slightly elevated on a background of normal serum calcium.

\begin{tabular}{lll}
\multicolumn{3}{l}{ Table 2. Hormonal and blood chemistry panel } \\
\hline Hormone & Result & Reference Interval \\
\hline Prolactin & 9,368 & $6.0-29 . \mathrm{ng} / \mathrm{mL} 9$ \\
TSH & 2.27 & $0.38-5.33 \mu \mathrm{lU} / \mathrm{mL}$ \\
LH & 2.26 & Postmenopause: $7.7-58.5 \mathrm{mlU} / \mathrm{mL}$ \\
FSH & 13.10 & Postmenopause: $26-135 \mathrm{mlU} / \mathrm{mL}$ \\
ACTH (8AM) & 20.50 & $<50 \mathrm{pg} / \mathrm{mL}$ \\
FT4 & 8.63 & $7.90-14.40 \mathrm{pmol} / \mathrm{L}$ \\
IGF-1 & 70.50 & $36.00-200.00 \mathrm{ng} / \mathrm{mL}$ \\
Cortisol (at 8AM) & 7.32 & $\mathrm{AM}: 8.7-22.4 / \mathrm{PM:}<10.0 \mu \mathrm{gg} / \mathrm{dL}$ \\
iPTH & 80.67 & $10.0-65.0 \mathrm{pg} / \mathrm{mL}$ \\
Calcium & 2.36 & $2.23-2.58 \mathrm{mmol} / \mathrm{L}$ \\
Sodium & 141.90 & $136-144 \mathrm{mmol} / \mathrm{L}$ \\
FBS & 7.41 & $4.10-6.60 \mathrm{mmol} / \mathrm{L}$ \\
\hline
\end{tabular}

Abbreviations: TSH - Thyroid Stimulating Hormone, LH - Luteinizing Hormone, FSH - Follicle Stimulating Hormone, ACTH - Adrenocorticotropic Hormone, FT4 - Free Thyroxine (T4), IGF-1 - Insulin-like Growth Factor-1, iPTH - intact Parathyroid Hormone, FBS - Fasting Blood Sugar.
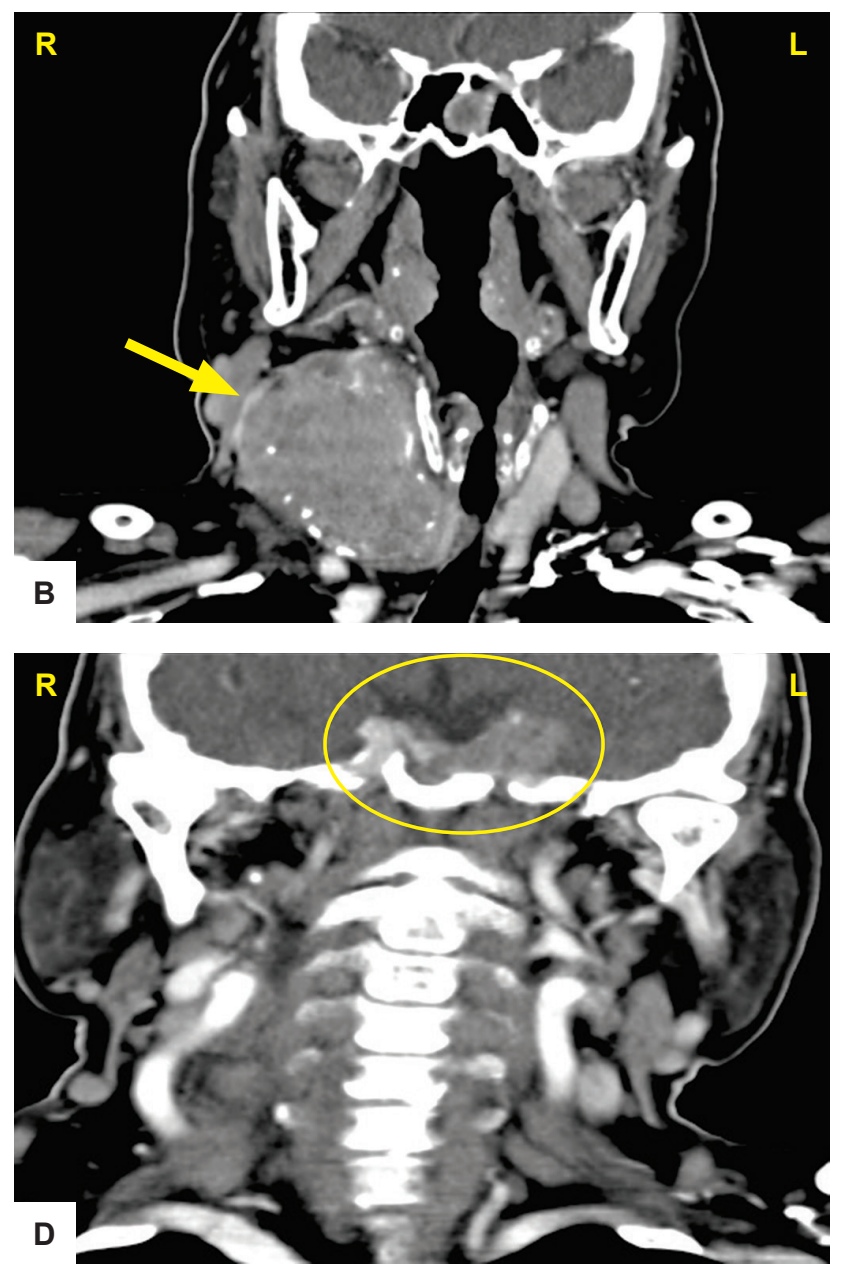

Figure 3. CT Scan with contrast of the head and neck. (A) Ulcerating mass (right nasolabial area); (B) $6.5 \times 5.0 \times 4.8 \mathrm{~cm}$ enhancing mass with peripheral calcifications (right thyroid lobe). Incidental left parasellar $2.3 \times 2.9 \times 3.6 \mathrm{~cm}$ enhancing mass with erosion of posterior wall of the sphenoid sinus and petrous apex in a (C) Cross-sectional view and in (D) Coronal view. 

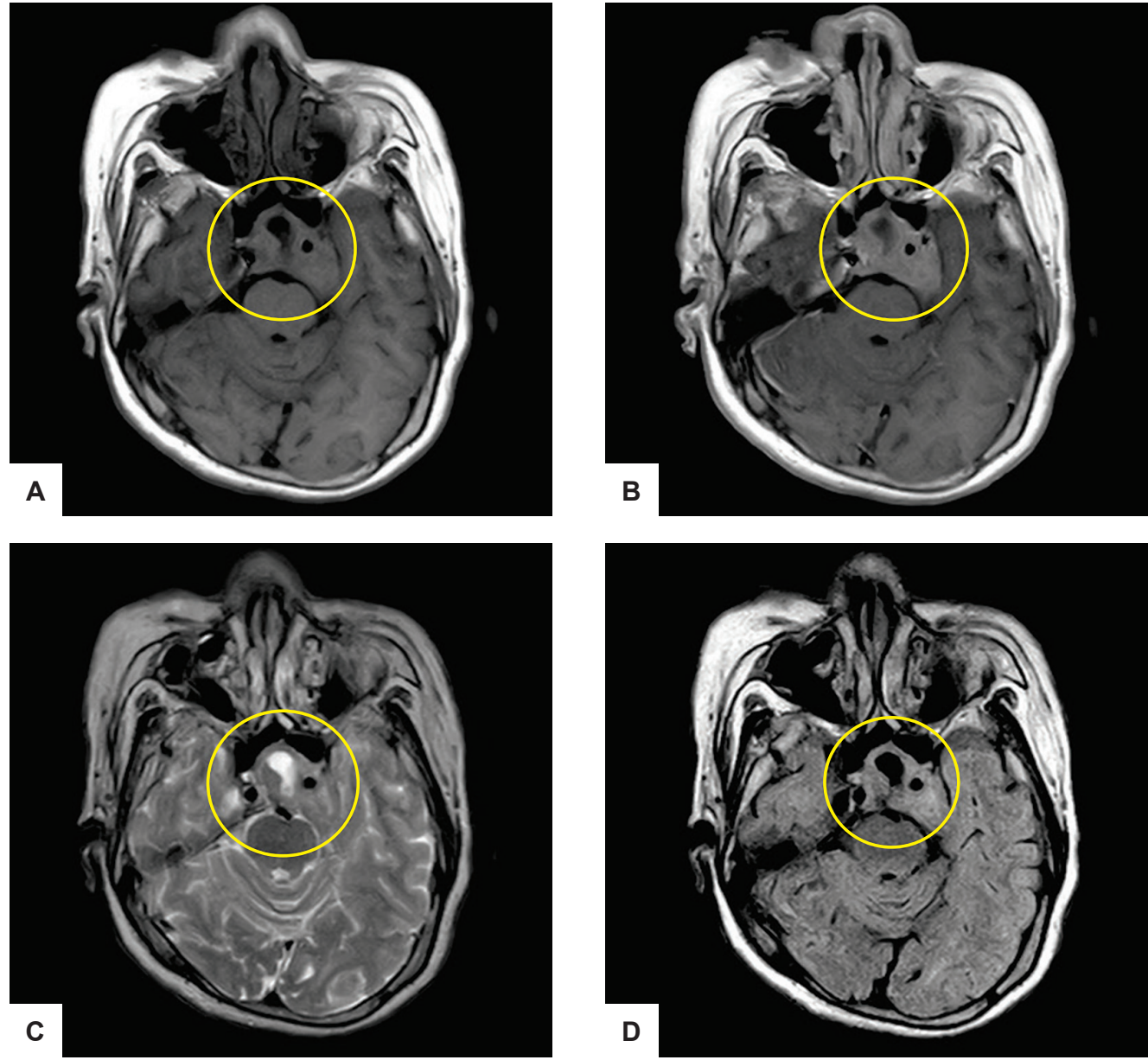

Figure 4. Cranial Magnetic Resonance Imaging (MRI). A $2.2 \times 3.1 \times 3.1 \mathrm{~cm}$ poorly defined complex mass predominantly solid in the sella with extension to left parasellar region. (A) T1 Weighted Image (T1WI) - Isointense (B) T1 contrast image Isointense (C) T2 Weighted Image (T2WI) - Mixed Signals (D) Fluid Attenuation Inversion Recovery (FLAIR) post gadolinium study - homogenous contrast enhancement. Noted encasement of the cavernous portion of the left carotid artery and bony destruction of the left petrous apex bone.

Ophthalmologic evaluation was normal except for a left quadrantanopsia on perimetry studies (Appendix B).

The patient underwent wide excision of the right nasolabial mass with frozen section biopsy for margins and total thyroidectomy. She was then started with synthetic thyroid hormone replacement. Final histopathologic report of the right nasolabial mass and thyroid mass revealed basal cell carcinoma and papillary thyroid carcinoma respectively as shown in Figures 5 and 6. The patient's final diagnosis was triple synchronous tumors with a combination of right nasolabial basal cell carcinoma, papillary thyroid carcinoma and prolactinoma.

While on bromocriptine, repeat serum prolactin after 6 weeks revealed an exponential decrease from a baseline of $9,368 \mathrm{ng} / \mathrm{mL}$ to a normal level at $16.17 \mathrm{ng} / \mathrm{mL}$. Dose of bromocriptine was decreased and the patient was advised to follow up for the surveillance tests. A postoperative radioactive iodine adjuvant therapy was the next plan for the patient.

\section{DISCUSSION}

Overall, it is estimated that there were 14.1 million new cases and 8.2 million deaths attributed to cancer worldwide. ${ }^{4}$
For Philippines, in 2015, the predicted number of new cases of cancer was about 109,280 and death from cancer was about 66,151 cases. $^{5}$

The three tumors presented by the patient have relatively common prevalence. Basal Cell Carcinoma (BCC) is the most common skin malignancy with prevalence estimated to be $2.0 \%, 1.4 \%$, and $0.7 \%$, for Australia, Europe, and the US, respectively. ${ }^{6,7}$ In Philippines, more than $60 \%$ of all skin cancers are of BCC. ${ }^{8}$ Papillary thyroid carcinoma (PTC) is the most common thyroid malignancy constituting $50 \%$ to $90 \%$ of well-differentiated thyroid carcinoma worldwide. ${ }^{9}$ Thyroid cancer was estimated to be the $8^{\text {th }}$ most common malignancy among Filipinos with an incidence of $2 \%{ }^{5}$ A local study conducted in the Philippine General Hospital - Otorhinolaryngology Department reported that $82.9 \%$ of thyroid malignancies admitted were PTC. ${ }^{10}$ Prolactinoma is the most common pituitary adenoma that accounts for up to $45 \%$ of pituitary tumors. ${ }^{11-13}$ Each tumor presented has a common prevalence but when all three are combined in a single patient, it becomes a rare occurrence.

The Disease and its International, National and Local Epidemiology

Albeit extensive literature reviews, there are no existing official registry that accounted triple primary tumors 

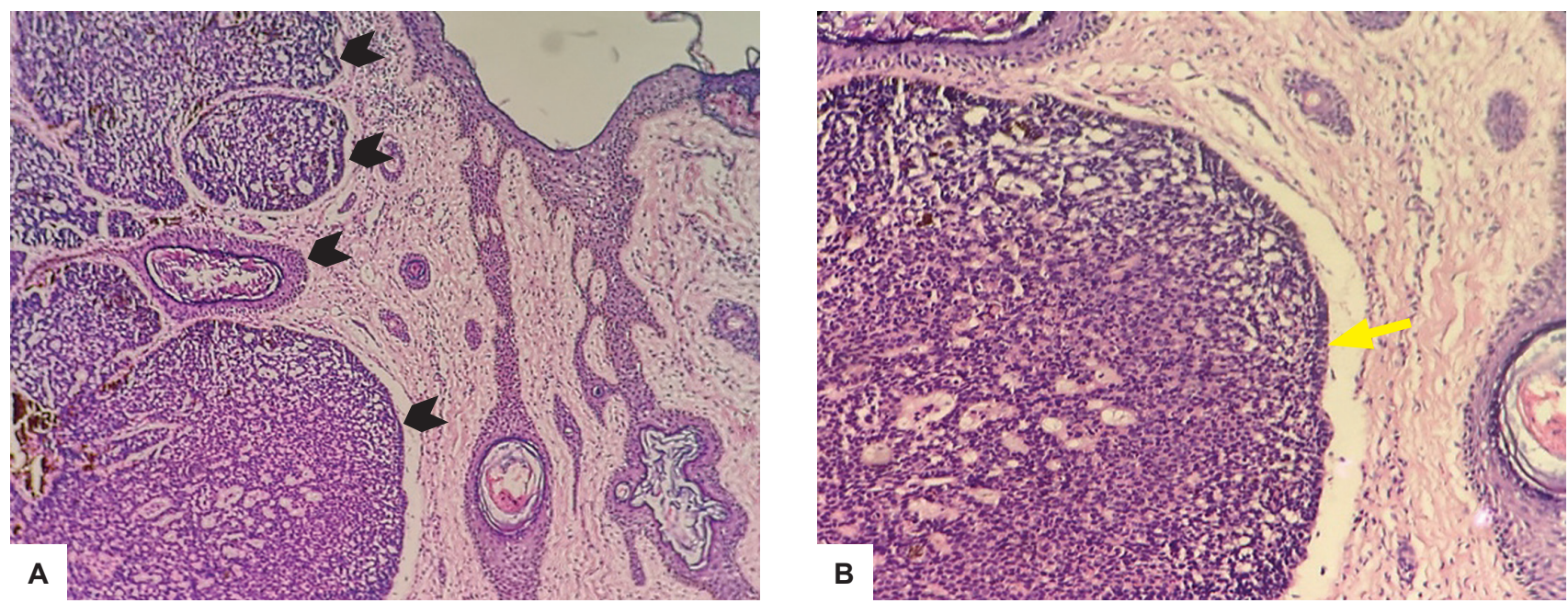

Figure 5. Histopathology report of nasolabial mass. (A) Nests \& sheets of atypical basaloid cells (H\&E, x40); (B) Atypical cells with palisading pattern at the periphery (H\&E, x100).
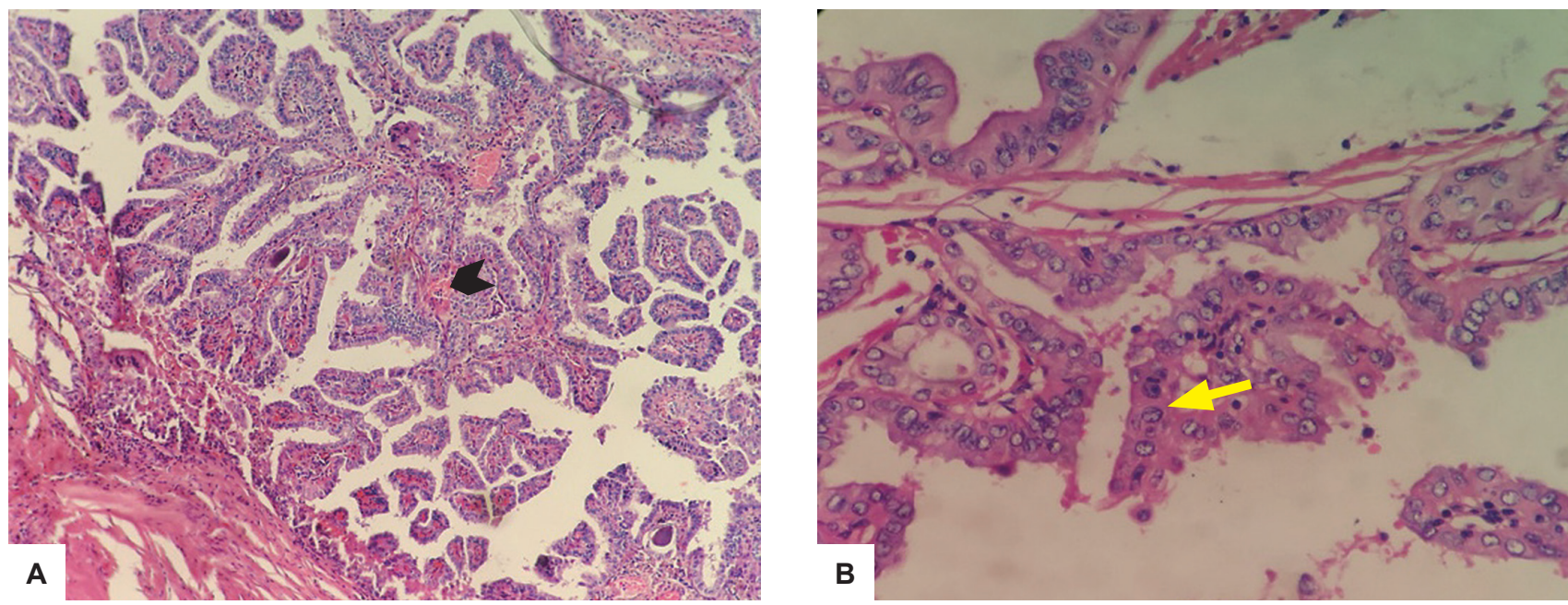

Figure 6. Histopathology report of thyroid mass. (A) Complex branching and randomly oriented papillae with fibrovascular core associated with follicles lined by atypical cells (H\&E, x40); (B) Atypical Cell with Orphan-Annie Nuclei and nuclear longitudinal grooves (H\&E, x400).

internationally, nationally and locally. A reported metaanalysis shows the frequency of second primary tumor as $3-5 \%$, a third tumor as $0.5 \%$ and a fourth tumor as $0.3 \% .^{1,2}$ In one study, the most common site of multiple primary tumors was head and neck, followed by gynecological cancers, breast cancer, lung cancer, and other cancers. ${ }^{2}$ Appendix C summarized documented case reports of triple primary tumors specific only to the head and neck reported in international published journals. Common in all these cases is the involvement of tumors from the skin, thyroid gland, and aerodigestive tract of the head and neck that were managed with surgical removal, adjuvant or neoadjuvant chemotherapy or radiotherapy. This case presented with right nasolabial BCC, PTC, and a prolactinoma which arose intracranially presenting with endocrinologic signs and symptoms. The rare combination of the three tumors was never reported and documented in a single patient among published international medical journals.

To date, there is no official case reports of triple primary malignancies in a single individual in the Philippines. However, a published case report in the Philippine Journal of Obstetrics and Gynecology documented triple primary tumors consisting of an ovarian cancer, an endometrial cancer and a uterine sarcoma in a 56-year-old single, nulligravid..$^{14}$ For multiple malignancies of head and neck, there are no documented and reported cases among national medical publications and even in our institution, making our patient as the first ever documented individual presenting with triple synchronous tumors of the head and neck with a rare combination of right nasolabial BCC, PTC, and prolactinoma.

\section{Clinical Manifestations and Clinical Correlation}

The diagnostic approach of multiple tumors in a single individual is challenging as it obviates the need to look into the possibility of metastases as one might be arising from the other. The occurrence of distant metastasis in BCC and PTC is very rare having a rate varying from $0.0028 \%$ to $0.55 \%$ and $1-7 \%$, respectively. The two most common sites of distant metastasis in both BCC and PTC are the lungs and bones. ${ }^{14-15}$ This case did not present with signs and symptoms of pulmonary and osseous metastases. Pituitary metastases occur in $\sim 3 \%$ of cancer patients. Blood borne metastasis are 
found almost exclusively in the posterior pituitary gland and about $50 \%$ of pituitary metastases originate from breast cancer. The patient has a normal breast examination and presented an anterior pituitary gland tumor, ruling out the possibility of a metastatic process. ${ }^{16}$

Having two tumors originating from different endocrine organs, it is very crucial not to miss multiple endocrine neoplasia (MEN) syndrome; most likely the MEN type 1 (MEN-1). MEN-1 or Wermer's syndrome has a clinical triad of tumors arising from the anterior pituitary gland, parathyroid gland, and pancreatic islets. ${ }^{17}$ No one in the family of the patient clinically presented with the endocrine tumors implicated in MEN-1. Appendix D summarized the program of tests and schedule for suspected MEN-1. 17,18 Intact parathyroid hormone was slightly elevated on a background of normal serum calcium and the fasting blood sugar was elevated. This ruled out hyperparathyroidism secondary to parathyroid adenoma, and pancreatic islet tumors which are the other components of MEN-1. Following the consensus on the schedule of tests, other recommended work up were not clinically indicated. The nature, origin and presentation of the three tumors did not fit a syndromic differential diagnosis.

The International Association of Cancer Registries and International Agency for Research on Cancer (IACR/IARC) utilize the 6-month rule interval to diagnosing synchronous from metachronous tumors arising from different sites regardless of the time of onset of each tumor. ${ }^{3}$ The patient had three tumors of different germline origins and locations. The manifestation of each tumor has different timeline of appearance however all three tumors were already manifested by the patient and were diagnosed within 6 months during the work up hence considered synchronous.

The patient's significant exposure to sun for a prolonged period as a vegetable street peddler was considered the most significant risk factor for BCC. ${ }^{14}$ A neck mass that moves with deglutition is consistent with a thyroid origin. It has a very straight forward clinical approach. A normal TSH as initial hormone assay will lead to the utilization of thyroid imaging (thyroid ultrasound) before doing biopsy. ${ }^{16}$ This was not done since a CT scan of head and neck was already performed.

Large sellar and suprasellar mass may impede the decussating fibers of the optic pathway and may present with bitemporal hemianopsia as its classic finding. Galactorrhea occurs in $80 \%$ of women with hyperprolactinemia. It also presents with secondary amenorrhea, infertility and loss of libido due to elevated prolactin that suppresses the pulsatile release of gonadotropin releasing hormone (GnRH) causing hypogonadotropic hypogonadism which were all seen in the patient. ${ }^{19}$ Surprisingly, the patient did not present with galactorrhea but it is worth noting that many premenopausal women with hyperprolactinemia do not have galactorrhea, and many with galactorrhea do not have hyperprolactinemia. This is because galactorrhea requires estrogenic or progesterone priming of the breast. Thus, galactorrhea is also very uncommon in postmenopausal women. ${ }^{20-22}$

As a rule of thumb, the diagnosis of endocrine diseases is clinical and biochemical or hormonal. Significant elevation of prolactin is $>200 \mathrm{ug} / \mathrm{L}(>200 \mathrm{ng} / \mathrm{mL})$ and is almost invariably indicative of a prolactin secreting pituitary adenoma. ${ }^{23,24} \mathrm{~A}$ "stalk effect" secondary to a large sellar mass as in this case may also increase serum prolactin levels due to obstruction of inhibitory dopamine flow from the hypothalamus. The elevation would usually fall between 96-200ng/mL and would not be too elevated, thus this was ruled out. ${ }^{24}$ All other causes for hyperprolactinemia were ruled out in this case. Evaluation of the hormones involved in the hypothalamus-pituitary-endocrine gland axis is imperative (Table 2). The low LH and FSH levels in this case can be attributed to the suppressive effects of high serum prolactin to the release of gonadotropin releasing hormone $(\mathrm{GnRH}) .{ }^{19}$ Growth hormone and ACTH synthesis and release are not affected by hyperprolactinemia. This explains why IGF-1 and ACTH are within normal levels. ${ }^{25}$ However, a low cortisol level on a background of low or normal ACTH seen in this case may point to a central adrenal insufficiency. It is prudent to include a dynamic study using synthetic ACTH (short synacthen test) to accurately diagnose adrenal insufficiency in the next follow up. ${ }^{26}$ Clinically the patient did not present with lethargy, hypotension, and hyponatremia hence the urgency for cortisol replacement was not warranted. Lastly an ophthalmologic evaluation and perimetry studies are salient in pituitary macroadenoma, as the involvement of the optic chiasm is crucial in the management. ${ }^{27}$

\section{Molecular Mechanisms and Genomics}

The concept of "field cancerization" in oncology has explained the occurrence of multiple tumors arising from the head and neck. It presumes that, after repeated carcinogenic exposures, the entire superficial epithelium of the upper aerodigestive tract has an increased risk of developing multifocal malignant lesions with tendency of locoregional recurrence. ${ }^{28,29}$ This theory can be applied to the development of right nasolabial BCC and PTC as well as all the reported cases of triple primary tumors (Appendix C). There are number of genetic mutations identified in genomic studies involving tumors arising from the head and neck but these are not found in the somatic mutation of prolactinoma which involves pituitary tumor transforming gene (PTTG) and fibroblast growth factor 4 (FGF4) ${ }^{30}$ This raises the question whether the prolactinoma has a different tumorogenesis coincidental to the other two tumors or are the three tumors associated with each other genetically since we have ruled out MEN in the case. Thus, this case report highly recommends a genetic analysis to be done in the patient to characterize the pattern or association of genetic mutations on her next follow up.

\section{Management}

The gold standard management for BCC and PTC is surgery with a goal of a zero border resection. Mohs micrographic surgery offers superior histologic analysis of tumor margins while permitting maximal conservation of tissue compared with standard excisional surgery for BCC however this was not performed to the patient wherein a wide excision was done. ${ }^{14}$ For PTC, total thyroidectomy is the surgery of choice which was done to the patient. It is followed with post-operative radioactive iodine adjuvant therapy which will be the next plan for the patient. A postoperative serum thyroglobulin and thyroglobulin antibody as well as an ultrasound of the thyroid bed will be monitored on top of the basic thyroid function tests to 
detect recurrence and evaluate surgical adequacy on the next follow up. ${ }^{31}$

The cornerstone management for prolactinoma is medical. All macroprolactinomas with a size of $>1 \mathrm{~cm}$ and symptomatic microprolactinomas with a size of $<1 \mathrm{~cm}$ warrant medical treatment. Having a pituitary tumor size of $2.2 \times 3.1 \times 3.1 \mathrm{~cm}$ on cranial MRI, patient was managed medically with dopamine agonist in the form of bromocriptine. ${ }^{17}$ Giving of bromocriptine which is a dopamine agonist simulates the inhibitory action of dopamine to the secretion of prolactin thus decreasing its levels and eventually promoting tumor shrinkage..$^{32}$ Dose of bromocriptine needs to be adjusted depending on medical response and will be given for approximately 1-2 years. Serum prolactin, cranial MRI and perimetry studies are part of the monitoring parameters for the management of prolactinoma and must be monitored during follow up. ${ }^{27}$ Prognosis of right nasolabial BCC, PTC and prolactinoma in one patient managed medically and surgically is not reported. Furthermore, there is no significant difference in the outcome of the separate tumours, if managed concurrently or separately since it is known that BCC, PTC and prolactinoma when managed individually like in our patient have a relatively good prognosis and have low incidence of recurrence. ${ }^{9,14}$

\section{CONCLUSION}

The incidence of the individual tumor presented by the patient is relatively common however the existence of three common tumors in a single patient is a rare occurrence. The rarity of the case prompted a challenge in diagnosing multiple tumors that involved multiple endocrine organs and hence this case report gives emphasis on two salient points.

First, accurate diagnosis is imperative for an accurate management. In approaching multiple tumors especially involving different endocrine organs, classifying the nature of the tumors whether primary, metastatic or syndromic is very crucial as it greatly impacts the management. The patient was spared from unnecessary surgical removal and complications from pituitary surgery as the cornerstone treatment for prolactinoma is medical. Accurate knowledge on disease prevalence, pathophysiology and symptomatology and correlation to guided history taking and astute physical examination is very important in rare medical conditions. Having this knowledge, we are guided and justified on what specific tests to run in order to work up the patient and rule out close differential diagnoses. Second, the multidisciplinary care approach ensures a holistic and comprehensive management of complicated cases and this case has greatly benefited from this. It has proven that even in the medical realm, more heads are better than one and even two.

\section{Ethical Consideration}

Patient consent was obtained before submission of the manuscript.

\section{Statement of Authorship}

All authors certified fulfillment of ICMJE authorship criteria.

\section{Author Disclosure}

The authors declared no conflicts of interest.

\section{Funding Source}

None.

\section{References}

1. Bittorf B, Kessler H, Merkel S, et al. Multiple primary malignancies: An epidemiological and pedigree analysis of 57 patients with at least three tumors. Eur J Surg Oncol. 2001;27(3):302-13. PMID: 11373110. https://doi.org/10.1053/ejso.2001.1112.

2. National Cancer Institute. SEER Program Code Manual, 3rd ed. Bethesda (MD): National Cancer Institute, 1998. https://seer.cancer. gov/archive/manuals/codeman.pdf.

3. North American Association of Central Cancer Registries. Howe $\mathrm{HL}$, ed. A review of the definition for multiple primary cancers in the United States: Workshop proceedings from December 4-6, 2002 in Princeton, New Jersey. https://citeseerx.ist.psu.edu/viewdoc/ download?doi=10.1.1.466.3479\&rep=rep1\&type=pdf.

4. Ferlay J, Soerjomataram I, Dikshit R, et al. Cancer incidence and mortality worldwide: Sources, methods and major patterns in GLOBOCAN 2012. Int J Cancer. 2015;136(5):E359-86. PMID: 25220842. https://doi.org/10.1002/ijc.29210.

5. Laudico AV, Mirasol-Lumague MR, Medina V, Mapua CA, Valenzuela FG, Pukkala E. 2015 Philippine cancer facts and estimates. Philippine Cancer Society: Manila, 2015. http://www.philcancer.org.ph/wpcontent/uploads/2017/07/2015-PCS-Ca-Facts-Estimates_CAN090516. pdf.

6. Apalla Z, Lallas A, Sotiriou E, Lazaridou E, Ioannides D. Epidemiological trends in skin cancer. Dermatol Pract Concept. 2017;7(2):1-6. PMID: 28515985. PMCID: PMC5424654. https://doi. org/10.5826/dpc.0702a01.

7. Leiter U, Eigentler T, Garbe C. Epidemiology of skin cancer. Adv Exp Med Biol. 2014;810:120-140. PMID: 25207363. https://doi. org/10.1007/978-1-4939-0437-2_7.

8. Saquian FYN. Basal cell carcinoma of the lip and mentum. Philipp J Otolaryngol Head Neck Surg. 2006;21(1,2):54-6.

9. Schlumberger MJ, Filetti S, Hay ID. Nontoxic diffuse and nodular goiter and thyroid neoplasia. In: Williams Textbook of Endocrinology, 12th ed, Ch. 14; 2011. https://doi.org/10.1016/B978-1-4377-03245.00014-6.

10. Gloria JDLS, Pontejos Jr AQY, Grullo PER. Risk factors for recurrent papillary thyroid carcinoma. Philipp J Otolaryngol Head Neck Surg. 2017;32(2):25-9. https://journal.pso-hns.org/wp-content/uploads/2017/ 11/orig-article-Risk-FactorS-2.pdf.

11. Arafah BM, Nasrallah MP. Pituitary tumors: Pathophysiology, clinical manifestations and management. Endocr Relat Cancer. 2001;8(4):287305. PMID: 11733226. https://doi.org/10.1677/erc.0.0080287.

12. Mindermann T, Wilson CB. Age-related and gender-related occurrence of pituitary adenomas. Clin Endocrinol (Oxf). 1994;41(3):359-64. PMID: 7893282. https://doi.org/10.1111/j.1365-2265.1994.tb02557.x.

13. Ciccarelli A, Daly AF, Beckers A. The epidemiology of prolactinomas. Pituitary. 2005;8(1):3-6. PMID: 16411062. https://doi.org/10.1007/ s11102-005-5079-0.

14. Carucci JA, Leffell DJ, Pettersen JS. Basal cell carcinoma. In: Fitzpatrick's Dermatology in General Medicine. Vol. 1, Ch. 115; 2012.

15. Portela RA, Choby GW, Manni A, Campbell D, Crist H, Goldenberg D. Unusual sites of metastasis of papillary thyroid cancer: Case series and review of the literature. Ear Nose Throat J. 2015;94(8):E43-7. PMID: 26322457.

16. Melmed S, Jameson L .Pituitary tumor syndromes. In: Harrison's Principles of Internal Medicine. 20th ed, Vol. 2, Ch. 373.

17. Cardino MJT, Lantion-Ang FL. Insulinoma and prolactinoma in young female: A variant of multiple endocrine endocrine neoplasia 1 (MEN-1). Philipp J Intern Med. 2009;47:137-42.https://www.pcp. org.ph/documents/PJIM/Volume\%2047\%20(2009)/Number\%203\%20 (May-June)/7-Insulinoma\%20and\%20Prolactinoma.pdf.

18. Brandi ML, Gagel RF, Bilezikian JP, et al. Guidelines for diagnosis and therapy of MEN type 1 and type 2. J Clin Endocrinol Metab. 2006;86(12):5658-71. PMID: 11739416. https://doi.org/10.1210/jcem. 86.12.8070.

19. Majumdar A, Mangal NS. Hyperprolactinemia. J Human Reprod Sci. 2013;6(3):168-75. PMID: 24347930. PMCID: PMC3853872. https://doi. org/10.4103/0974-1208.121400.

20. Kleinberg DL, Noel GL, Frantz AG. Galactorrhea: A study of 235 cases including 48 with pituitary tumors. N Engl J Med. 1977;296(11):589600. PMID: 840242. https://doi.org/10.1056/NEJM197703172961103.

21. Tolis G, Somma M, Campenhout JV, Friesen H. Prolactin secretion in sixty-five patients with galactorrhea. Am J Obstet Gynecol. 1974;118(1):91-101. PMID: 4202979. https://doi.org/10.1016/s0002-9378 (16)33651-1.

22. Boyd 3rd AE, Reichlin S, Turksoy RN . Galactorrhea-amenorrhea syndrome: Diagnosis and therapy. Ann Intern Med. 1977;87(2);165-75. PMID: 407824. https://doi.org/10.7326/0003-4819-87-2-165.

23. Kawaguchi T, Ogawa Y, Tominaga T. Diagnostic pitfalls of hyperprolactinemia: The importance of sequential pituitary imaging. 
BMC Res Notes. 2014;7:555. PMID: 25142896. PMCID: PMC4148930. https://doi.org/10.1186/1756-0500-7-555.

24. Shucart WA. Implications of very high serum prolactin levels associated with pituitary tumors. J Neurosurg. 1980;52(2):226-8. PMID 7351562. https://doi.org/10.3171/jns.1980.52.2.0226.

25. Lugo G, Pena L, Cordido F. Clinical manifestations and diagnosis of acromegaly. Int J Endocrinol. 2012;2012:540398. PMID: 22518126. PMCID: PMC3296170. https://doi.org/10.1155/2012/540398.

26. Bornstein SR, Allolio B, Arlt W, et al. Diagnosis and treatment of primary adrenal insufficiency: An Endocrine Society Clinical Practice Guideline. 2016;101(2):364-89. PMID: 26760044. PMCID: PMC4880116. https://doi.org/10.1210/jc.2015-1710.

27. Schlechte J.. Approach to the patient: Long term management of prolactinomas. J Clin Endocrinol Metab. 2017;92(8):2861-5. https://doi. org/10.1210/jc.2007-0836.

28. Wei ZH, Gong W, Zhou M, Chen QM. The concept of field cancerization and its clinical application. Zhonghua Kou Qiang Yi Xue Za Zhi. 2016;51(9):562-5. PMID: 27596348. https://doi.org/10.3760/ cma.j.issn.1002-0098.2016.09.011.

29. Mohan M, Jagannathan N. Oral field cancerization: An update on current concepts. Oncol Rev. 2014; 8(1): 244. PMID: 25992232. PMCID PMC4419611. https://doi.org/10.4081/oncol.2014.244.

30. Yatavelli RKR, Bhusal K. Prolactinoma. In: StatPearls [Internet] Treasure Island (FL): StatPearls Publishing; 2020 Jan. 2020 Aug 10. PMID: 29083585. NBK459347.

31. Indrasena BSH. Use of thyroglobulin as a tumour marker. World J Biol Chem. 2007;8(1): 81-5. PMID: 28289520. PMCID: PMC5329716. https://doi.org/10.4331/wjbc.v8.i1.81.
32. Lyons DJ, Hellysaz A, Broberger C. Prolactin regulates tuberoinfundibular dopamine neuron discharge pattern: Novel feedback control mechanisms in the lactotrophic axis. J Neurosci. 2012 32(23):8074-83. PMID: 22674282. PMCID: PMC6620951. https://doi org/10.1523/JNEUROSCI.0129-12.2012.

33. Shah M, Agarwal R, Gupta S, et al. Triple primary malignancies in head-and-neck region: A report of four cases. South Asian J Cancer 2017;6(4):194-5. PMID: 29404306. PMCID: PMC5763638. https://doi. org10.4103/sajc.sajc_225_17.

34. Singh NJ, Tripathy N, Roy P, Manikantan K, Arun P. Simultaneou triple primary head and neck malignancies: A rare case report. Head and Neck Pathol. 2016;10(2):233-6. PMID: 26477035. PMCID: PMC4838955. https://doi.org/10.1007/s12105-015-0664-7.

35. Yalavarthi S, Pamu PK, Thoondla M, Gupta S. Metachronous malignancies in head and neck region: Report of two cases. Indian J Pathol Microbiol. 2014;57(2):314-6. PMID: 24943776. https://doi org/10.4103/0377-4929.134728.

36. Umeshappa H, Chandrashekhar M, Shenoy AM, Dinesh Kumar GR. Triple simultaneous primary tumors of the head and neck: A rare case report. Int J Case Rep Images 2014;5(7):488-91. https://doi.org/10.5348/ ijcri-201485-CR-10396.

37. Nishikawa K, Kawada J, Fujitani K, et al. A case of metachronous triple cancer with multimodal approach including surgical resection. Gan To Kagaku Ryoho. 2014;41(12):2033-5. PMID: 25731413

38. Clarke DR, Smallman LA, Rhys-Evans PH. Triple primary malignan neoplasms in the head and neck. J R Soc Med. 1986;79(11):676-7. PMID: 3795214. PMCID: PMC1290538.

Authors are required to accomplish, sign and submit scanned copies of the JAFES Author Form consisting of: (1) Authorship Certification, that authors contributed substantially to the work, that the manuscript has been read and approved by all authors, and that the requirements for authorship have been met by each author; (2) the Author Declaration, that the article represents original material that is not being considered for publication or has not been published or accepted for publication elsewhere, that the article does not infringe or violate any copyrights or intellectual property rights, and that no references have been made to predatory/ suspected predatory journals; (3) the Author Contribution Disclosure, which lists the specific contributions of authors; and (4) the Author Publishing Agreement which retains author copvright, grants publishing and distribution rights to JAFES, and allows JAFES to apply and enforce an Attribution-Non-Commercial Creative Commons user license. Authors are also required to accomplish, sign, and submit the signed ICMJE form for Disclosure of Potential Conflicts of Interest. For original articles, authors are required to submit a scanned copy of the Ethics Review Approval of their research as well as registration in trial registries as appropriate. For manuscripts reporting data from studies involving animals, authors are required to submit a scanned copy of the Institutional Animal Care and Use Committee approval. For Case Reports or Series, and Images in Endocrinology, consent forms, are required for the publication of information about patients; otherwise, appropriate ethical clearance has been obtained from the institutional review board. Articles and any other material published in the JAFES represent the work of the author(s) and should not be construed to reflect the opinions of the Editors or the Publisher.

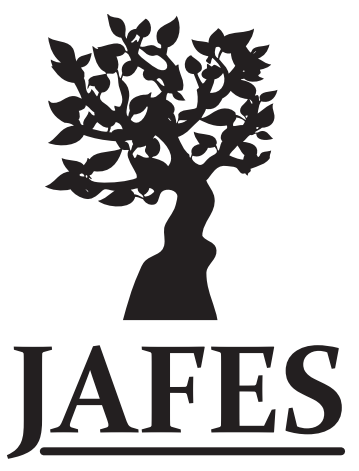

\section{Unique, interesting, enlightening. Your case report and the JAFES.}




\section{APPENDICES}

Appendix A. Family Pedigree
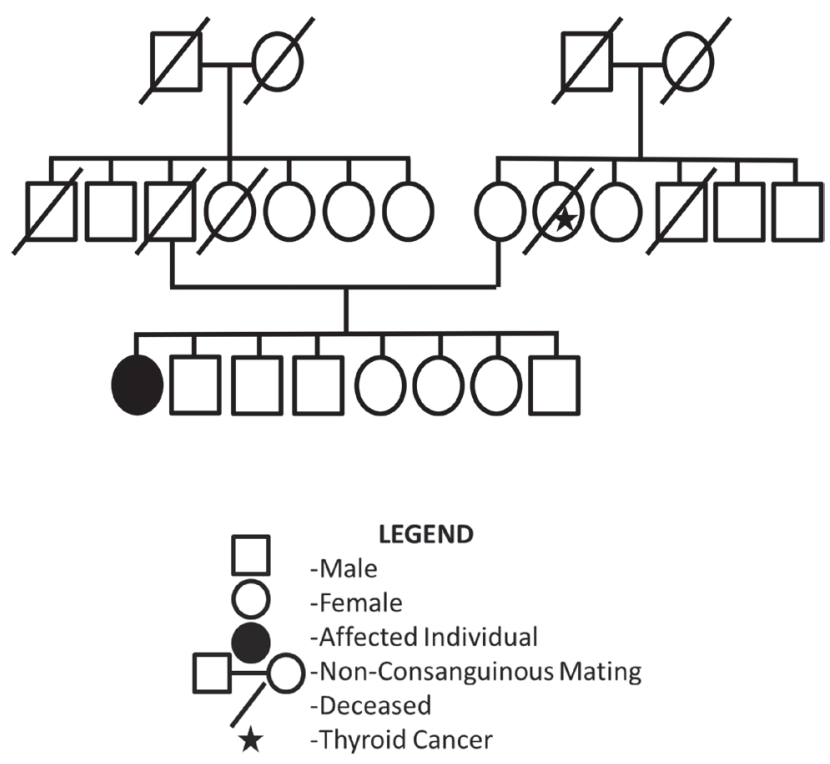

\section{Appendix B. Octopus Perimetry Study Report}

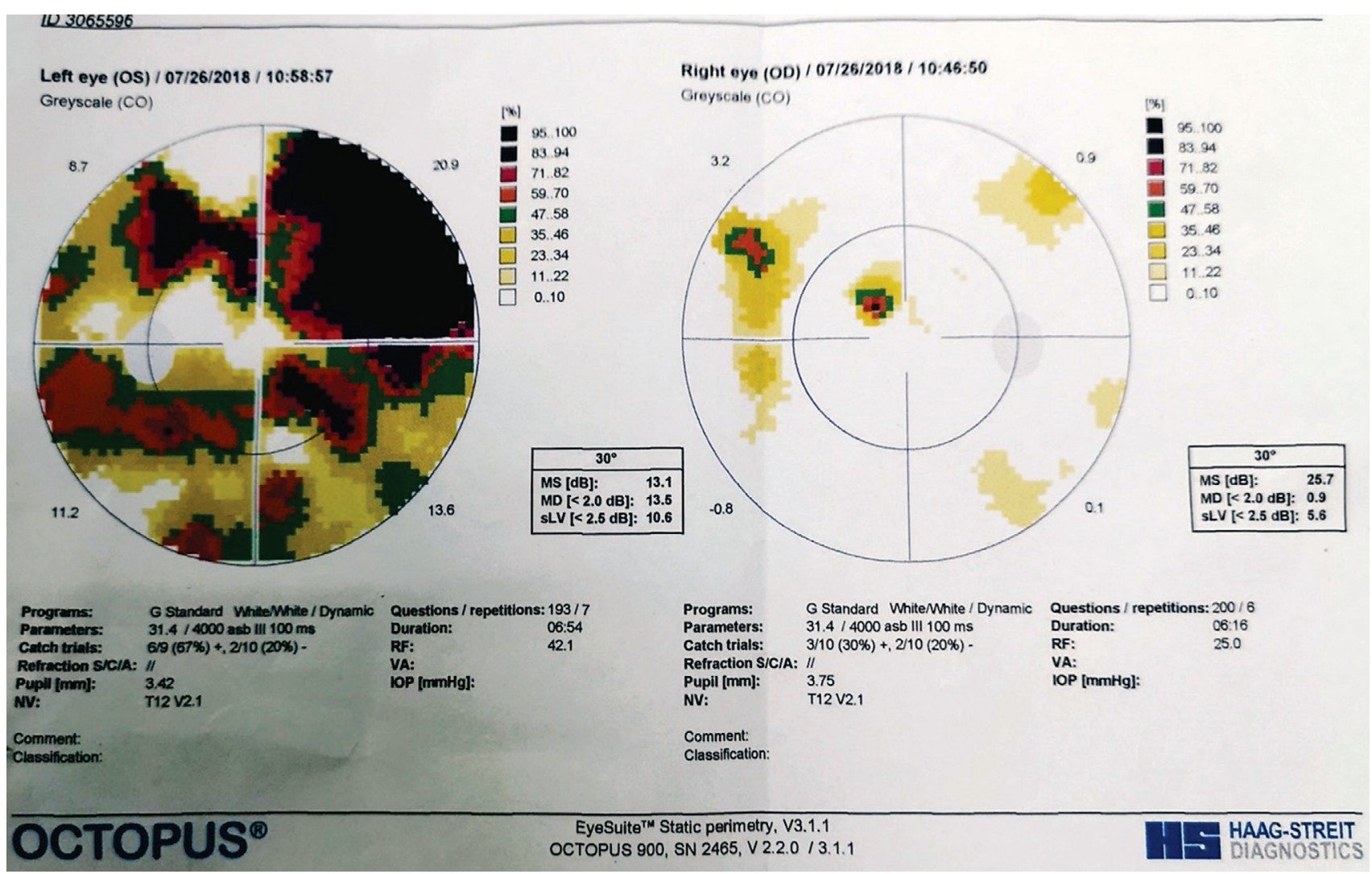

This perimetry study reports normal visual field of the right eye and a finding of a left Quadrantanopsia. However this perimetry study was taken with poor validity having a positive catch of $67 \%$ and a negative catch of $21 \%$. A repeat study is recommended. 


\section{Appendix C. Case reports of triple primary tumors specific only to the head $\&$ neck ${ }^{33-38}$}

\begin{tabular}{|c|c|c|c|}
\hline Author & Features & Age & Management \\
\hline \multirow{4}{*}{$\begin{array}{l}\text { Shah, M. et al } \\
\text { India } \\
(2017)^{33}\end{array}$} & $\begin{array}{l}\text { Case \#1 } \\
\text { 1. Carcinoma left buccal Mucosa } \\
\text { 2. Carcinoma left upper alveolus and hard palate } \\
\text { 3. Carcinoma right side base of tongue }\end{array}$ & - & $\begin{array}{l}\text { 1. Wide local excision + left supra-omohyoid neck dissection + } \\
\text { radiation } \\
\text { 2. Subtotal maxillectomy with free flap reconstruction + re-irradiation } \\
\text { with concurrent chemotherapy } \\
\text { 3. Near total glossectomy + right modified radical neck dissection + } \\
\text { re-irradiation }\end{array}$ \\
\hline & $\begin{array}{l}\text { Case \#2 } \\
\text { 1. Carcinoma left tonsil } \\
\text { 2. Carcinoma left lateral tongue } \\
\text { 3. Carcinoma cervical esophagus }\end{array}$ & - & $\begin{array}{l}\text { 1. Radiation with concurrent chemotherapy } \\
\text { 2. Wide local excision + ipsilateral radical neck dissection } \\
\text { 3. Neoadjuvant chemotherapy followed by re-irradiation and } \\
\text { concurrent chemotherapy }\end{array}$ \\
\hline & $\begin{array}{l}\text { Case \#3 } \\
\text { 1. Carcinoma vallecular } \\
\text { 2. Carcinoma-in-situ middle esophagus } \\
\text { 3. Carcinoma post cricoid } \\
\end{array}$ & - & $\begin{array}{l}\text { 1. Radiation } \\
\text { 2. Re-irradiation with concurrent chemotherapy } \\
\text { 3. Neoadjuvant chemotherapy followed by re-irradiation }\end{array}$ \\
\hline & $\begin{array}{l}\text { Case \#4 } \\
\text { 1. Carcinoma right buccal mucosa } \\
\text { 2. Carcinoma right lateral tongue } \\
\text { 3. Carcinoma glottis }\end{array}$ & - & $\begin{array}{l}\text { 1. Wide local excision + supraomohyoid neck dissection + adjuvant } \\
\text { radiation } \\
\text { 2. Hemiglossectomy + re-irradiation with concurrent chemotherapy } \\
\text { 3. Palliative Chemotherapy }\end{array}$ \\
\hline $\begin{array}{l}\text { Singh, N. et al } \\
\text { India } \\
(2015)^{34}\end{array}$ & $\begin{array}{l}\text { 1. Squamous cell carcinoma of larynx } \\
\text { 2. Papillary thyroid carcinoma } \\
\text { 3. Non-Hodgkin's Lymphoma }\end{array}$ & 71 yo & $\begin{array}{l}\text { 1. Total laryngectomy with } \\
\text { 2. Total thyroidectomy and bilateral selective neck dissection + } \\
\text { adjuvant radiation followed by radioactive iodine ablation } \\
\text { 3. Chemotherapy (Cyclophoshamide and Dexamethasone) }\end{array}$ \\
\hline $\begin{array}{l}\text { Yalavarthi, S. et al } \\
\text { India } \\
(2014)^{35} \\
\end{array}$ & $\begin{array}{l}\text { 1. Hodgkin's lymphoma } \\
\text { 2. Mucoepidermoid carcinoma of the salivary gland } \\
\text { 3. Follicular variant of papillary thyroid carcinoma }\end{array}$ & 21 yo & $\begin{array}{l}\text { 1. Chemotherapy } \\
\text { 2. Not mentioned } \\
\text { 3. Left hemithyroidectomy }\end{array}$ \\
\hline $\begin{array}{l}\text { Umeshappa, H. et al } \\
\text { India } \\
(2014)^{36}\end{array}$ & $\begin{array}{l}\text { 1. Adenoid cystic carcinoma of left parapharyngeal } \\
\text { mass } \\
\text { 2. Follicular thyroid carcinoma } \\
\text { 3. Basal cell carcinoma of the right upper lip }\end{array}$ & 63 yo & $\begin{array}{l}\text { 1. Transparotid-trancervical excision + supraomohyoid neck } \\
\text { dissection + adjuvant chemotherapy } \\
\text { 2. Left thyroid lobectomy with frozen section with concurrent } \\
\text { completion thyroidectomy with central neck compartment } \\
\text { dissection + radioactive iodine } \\
\text { 3. Wide local excision }\end{array}$ \\
\hline $\begin{array}{l}\text { Nishikawa, K et al } \\
\text { Japan } \\
(2014)^{37}\end{array}$ & $\begin{array}{l}\text { 1. Hypopaharyngeal cancer } \\
\text { 2. Esophageal cancer } \\
\text { 3. Tongue cancer }\end{array}$ & 37 yo & $\begin{array}{l}\text { 1. Hypopaharyngealectomy and cervical lymphadenectomy + } \\
\text { adjuvant Radiotherapy } \\
\text { 2. Esophagectomy } \\
\text { 3. Partial and subtotal resection of tongue }\end{array}$ \\
\hline $\begin{array}{l}\text { Clarke DR. et al } \\
\text { UK } \\
(1986)^{38}\end{array}$ & $\begin{array}{l}\text { 1. Papillary thyroid carcinoma } \\
\text { 2. Squamous cell carcinoma of the left vocal cord } \\
\text { 3. Squamous cell carcinoma and lymphoma of the } \\
\text { left posterior mandible }\end{array}$ & 43 yo & $\begin{array}{l}\text { 1. Subtotal thyroidectomy } \\
\text { 2. Laryngectomy and left radical neck dissection } \\
\text { 3. Chemotherapy }\end{array}$ \\
\hline
\end{tabular}

\section{Appendix D. Program of tests, and schedule for suspected MEN-1}

\begin{tabular}{lrcc}
\multicolumn{1}{c}{ Tumor } & Age & Biochemical Test (Annual) & Imaging \\
\hline Parathyroid Adenoma & 8 & Calcium, PTH & None \\
Gastrinoma & 20 & Gastrin & None \\
Insulinoma & 5 & FBS, Insulin & MRI \\
Anterior Pituitary Tumor & 5 & Prolactin, IGF-1 & MRI \\
Foregut Carcinoid & 20 & None & CT-Scan \\
\hline${ }^{*}$ Adapted from the Consensus Guidelines for MEN-1 and MEN-2 ${ }^{19,20}$ &
\end{tabular}

